\title{
Five year study of prenatal testing for Huntington's disease: demand, attitudes, and psychological assessment
}

\author{
S Adam, S Wiggins, P Whyte, M Bloch, M H K Shokeir, H Soltan, W Meschino, \\ A Summers, O Suchowersky, J P Welch, M Huggins, J Theilmann, M R Hayden
}

Department of Medical Genetics, University of British Columbia, Room 416 2125 East Mall, Vancouver, BC, Canada V6T 1Z4.

$S$ Adam

$S$ Wiggins

P Whyte

M Bloch

M Huggins

J Theilmann

M R Hayden

Department of Paediatrics, Medical Genetics, University of Saskatchewan, Canada.

M H K Shokeir

University of Western Ontario, Regional Medical Genetics Centre, Canada.

H Soltan

Clinical Genetics Diagnostic Centre, North York Genera Hospital, Canada.

W Meschino

A Summers

Department of Clinical Neurosciences and Genetics

University of Calgary,

Canada.

O Suchowersky

\section{Atlantic Research} Centre for Dalhousie University, Dalhousie University, Canada.

J P Welch

Correspondence to Professor Hayden.

Received 11 December 1992. Accepted 29 April 1993.

\begin{abstract}
Adult predictive and prenatal testing programmes for Huntington's disease (HD) in Canada have been available since 1986. However, the demand for prenatal testing and the reasons why some people choose not to have the prenatal test for this late onset disorder have not been well documented. In addition, the knowledge and attitudes of adult predictive testing candidates and their partners about prenatal testing are not well known nor are the psychological effects of prenatal testing well understood. As of September 1991, 425 subjects had entered the Canadian Collaborative Study of Predictive Testing and, of these, 47 subjects or their partners had become pregnant. Of this group, $14(30 \%)$ couples requested prenatal testing, $24(51 \%)$ couples did not want prenatal testing, and nine $(19 \%)$ at risk subjects had already received a decreased risk through adult predictive testing and, therefore, were not eligible for the prenatal test. Of the 14 couples who initially requested prenatal testing, seven withdrew. Thus, demand for the prenatal test by eligible candidates was $7 /$ 38 or $18 \%$, which is much lower than the 32 to $65 \%$ expected based on early survey data. The most frequently cited reason for declining prenatal testing was the hope that a cure would be found in time for their children. While the majority of adult predictive testing candidates $(71 \%)$ in our study had accurate information about definitive prenatal testing, many $(63 \%)$ did not have a correct understanding of exclusion prenatal testing. Although no serious adverse events such as suicide planning or admission to psychiatric hospital have occurred, a particular need for careful counselling was identified for those at risk candidates and their partners who have one prenatal test and feel compelled to use the test again in future pregnancies. Even though prenatal testing for $H D$ is not requested as often as originally expected, it still remains a desired option for some at risk persons and their partners.

(f Med Genet 1993;30:549-56)
\end{abstract}

The identification of closely linked DNA restriction fragment length polymorphisms has made both prenatal and adult predictive testing possible for many adult onset disorders including polycystic kidney disease, ${ }^{1}$ familial Alzheimer's disease, ${ }^{2}$ familial CreutzfeldtJakob disease, and Huntington's disease (HD). ${ }^{3-6}$ In the last few years, adult predictive testing for $\mathrm{HD}$ has received international attention. However, little is known about the acceptability and demand for prenatal testing. Furthermore, the factors influencing the decision to use prenatal testing for this currently incurable, adult onset disorder are not well understood.

Prenatal testing for HD can be offered in various ways. ${ }^{7}$ 'Exclusion' prenatal testing is possible when the at risk parent is at $50 \%$ risk for HD and either does not wish or is unable to determine his or her own risk for HD. This kind of testing allows the risk of the fetus to be altered from $25 \%$ to either very low (that is, excluded) or approximately $50 \%$ (that is, the same as the at risk parent), depending on which of the grandparents' chromosomes the fetus has inherited. 'Definitive' prenatal testing is available for a parent affected with HD or at increased risk for HD through predictive testing. Using this approach, the risk of the fetus is altered from approximately $50 \%$ to very high (approximately $96 \%$ ) or very low (2 or $3 \%$ ). The final option is a stepwise combination of the above two approaches, or 'exclusion-definitive' testing. The first step of the prenatal test would be exclusion testing. If the fetus was found to be at low risk (that is, excluded), no further testing would be necessary. However, if the fetus was found to have a risk similar to that of the at risk parent (that is, approximately $50 \%$ ), the next step would be to perform a predictive test for the parent. In this way, the status of the fetus would be determined simultaneously with the status of the parent.

Before predictive testing became widely available, four American studies ${ }^{8-11}$ investigated attitudes towards adult predictive and prenatal testing for HD. In these studies, 63 to $79 \%$ of the at risk subjects surveyed said they would use adult predictive testing while only 32 to $65 \%$ said they would use, or would have used, prenatal testing if it was available. It is difficult to use these studies to judge the demand for prenatal testing, though, because the subjects who completed the surveys were responding to a hypothetical situation. Moreover, the survey samples included persons who were beyond childbearing age or had already completed their families. Nevertheless, in each study, the number of subjects who said they would use prenatal testing was fewer than the 
number who indicated they would use adult predictive testing.

Studies of those who have participated in prenatal testing for HD are scarce and generally limited to case reports. ${ }^{12-15}$ To date, there have been only two studies which have attempted to assess the levels of uptake. Craufurd et $a l^{16}$ reported that while $81 \%$ of their 109 candidates said they would request prenatal testing if pregnant, only three couples had the prenatal test. In contrast, 33 adult predictive tests were performed. Unfortunately, the authors did not report how many of the candidates became pregnant and chose not to use prenatal testing. In the second study, Tyler et $a l^{17}$ offered only exclusion prenatal testing and no adult predictive testing at the outset of their programme. Fifteen of the 90 $(16.7 \%)$ couples referred to their centre over a three year period participated in prenatal testing. However, it is difficult to estimate the demand for prenatal testing from this study as some persons might first have had an adult predictive test had it been available. A low risk adult predictive testing result would have obviated the need for prenatal testing.

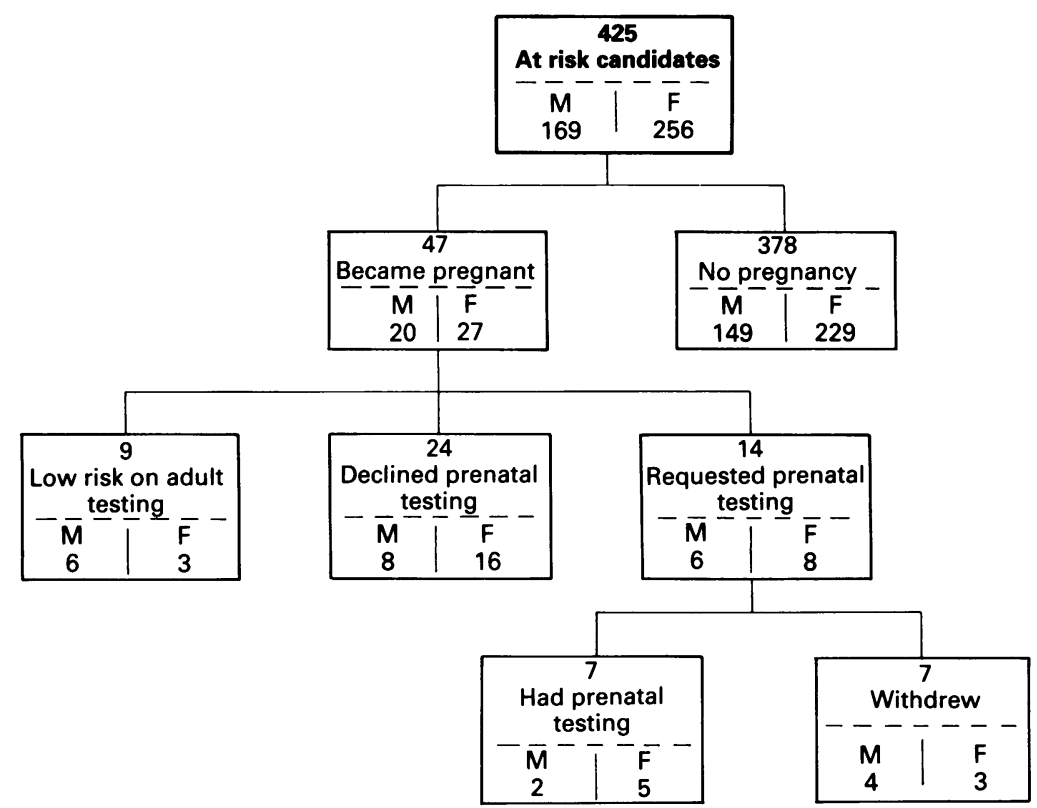

Diagram indicating the decisions made by predictive testing candidates and their partners regarding prenatal testing for Huntington's disease.

Table 1 Responses by age and sex of at risk candidates to the question: "If you or your spouse were pregnant, would you use the predictive test for prenatal diagnosis?" $(n=390$ responses, missing $=10)$.

\begin{tabular}{|c|c|c|c|c|}
\hline & \multicolumn{3}{|c|}{ Age categories } & \multirow[b]{2}{*}{ Total } \\
\hline & $\begin{array}{c}<30 \\
\text { No }(\%)\end{array}$ & $\begin{array}{c}30-40 \\
\text { No }(\%)\end{array}$ & $\begin{array}{c}>40 \\
\text { No }(\%)\end{array}$ & \\
\hline \multicolumn{5}{|l|}{ All candidates } \\
\hline Yes & $37(33 \cdot 6)$ & $73(44 \cdot 0)$ & $59(51 \cdot 8)$ & $169(43 \cdot 3)$ \\
\hline No & $25(22 \cdot 8)$ & $48(28.9)$ & $15(13 \cdot 1)$ & $88(22 \cdot 6)$ \\
\hline Uncertain & $48(43 \cdot 6)$ & $45(27 \cdot 1)$ & $40(35 \cdot 1)$ & $133(34 \cdot 1)$ \\
\hline $\begin{array}{l}\text { Total } \\
\text { p value }\end{array}$ & $110(100)$ & $166(100)$ & $114(100)$ & $\begin{array}{c}390(100) \\
0.002\end{array}$ \\
\hline \multicolumn{5}{|c|}{ Female candidates } \\
\hline Yes & $24(33 \cdot 3)$ & $43(45 \cdot 7)$ & $39(56 \cdot 5)$ & $106(45 \cdot 1)$ \\
\hline No & $19(26 \cdot 4)$ & $28(29 \cdot 8)$ & $8(11 \cdot 6)$ & $55(23 \cdot 4)$ \\
\hline Uncertain & $29(40 \cdot 3)$ & $23(24 \cdot 6)$ & $22(31.9)$ & $74(31.5)$ \\
\hline Total & $72(100)$ & $94(100)$ & $69(100)$ & $235(100)$ \\
\hline p value & & & & 0.009 \\
\hline \multicolumn{5}{|c|}{ Male candidates } \\
\hline Yes & $13(34 \cdot 2)$ & $30(41 \cdot 7)$ & $20(44 \cdot 4)$ & $63(40 \cdot 6)$ \\
\hline No & $6(15 \cdot 8)$ & $20(27 \cdot 8)$ & $7(15 \cdot 6)$ & $33(21 \cdot 3)$ \\
\hline Uncertain & $19(50 \cdot 0)$ & $22(30 \cdot 6)$ & $18(40 \cdot 0)$ & $59(38 \cdot 1)$ \\
\hline $\begin{array}{l}\text { Total } \\
\text { p value }\end{array}$ & $38(100)$ & $72(100)$ & $45(100)$ & $155(100)$ \\
\hline
\end{tabular}

In this paper, we report on our experience with prenatal testing in the Canadian Collaborative Study on Predictive Testing (CCSPT) for Huntington's Disease. A major objective of the present study was to assess the demand for prenatal testing. The CCSPT is particularly suited to look at this issue because of its large size and the availability of both prenatal and adult predictive testing for HD from the outset of the programme. Additional objectives were to ascertain why some pregnant women and their partners decline prenatal testing and to evaluate the psychological effects of testing on those who choose to have the prenatal test.

\section{Methods}

SUBJECTS

Adult predictive and prenatal testing for HD began in British Columbia in 1986 and became available across Canada in 1988. At risk subjects were notified about the programme through the Huntington's Society of Canada Newsletter and various media sources such as television and newspapers. Furthermore, in some areas, letters were sent to at risk subjects known to the local Genetics Centre.

As of September 1991, 425 at risk men $(n=169)$ and women $(n=256)$ had entered the CCSPT, and 47 of these or their partners had become pregnant (figure). Nine of the women became pregnant after they or their partner had received a decreased risk result through adult predictive testing. Therefore, for these men and women prenatal testing became an irrelevant issue. Of the remaining 38 couples, $14(37 \%)$ requested prenatal testing while 24 $(63 \%)$ did not wish to undergo prenatal testing.

\section{PROCEDURES}

All adult predictive testing candidates participated in a protocol of psychosocial assessment and pre- and post-test counselling. ${ }^{18} \mathrm{~A}$ very similar protocol was followed by prenatal testing candidates and, where possible, their partners. Couples who requested more than one prenatal test restarted the protocol with each pregnancy.

During their first pre-test assessment session, adult predictive testing candidates completed a questionnaire designed to assess their knowledge about and attitudes towards both adult predictive and prenatal predictive testing. ${ }^{18}$ Partners did not complete this questionnaire. Knowledge of the at risk candidates about specific aspects of definitive and exclusion prenatal testing was assessed by five true or false questions. To evaluate attitudes towards prenatal testing, candidates were asked whether they would use prenatal testing (table 1). A second question asked what they would do if the fetus was shown to have an increased risk. Responses to the two attitude questions were tabulated according to three age categories of respondents: those under 30 years of age, those between 30 and 40 years of age, and those over 40 years of age. Responses of at risk 
candidates to those two questions were also tabulated separately for males and females.

The psychosocial assessment consisted of an extensive battery of demographic and psychosocial questionnaires used to assess current psychological status. Two instruments were selected as measures of particular interest. The General Severity Index (GSI) of the Symptom Checklist 90-R (SCL90(R)) measures the general level of psychiatric distress. ${ }^{19}$ This test has been standardised on a general adult population and has a mean of 50 and a standard deviation of 10. A second instrument, the Beck Depression Inventory (BDI), measures depression..$^{20} \mathrm{~A}$ score above 10 on this scale is considered to be indicative of a clinical depression.

Another questionnaire was later developed and mailed to the 24 at risk subjects who were eligible for, but chose not to use, prenatal testing. The questionnaire asked them for information concerning the number and outcome of pregnancies which had occurred since their entry into the CCSPT. They were also asked about their risk status and their attitudes towards a termination of pregnancy. Finally, they were asked to indicate their five most important reasons for not choosing prenatal testing. A similar questionnaire was sent to the partners of the at risk candidates.

\section{DNA ANALYSIS}

Blood samples were taken from each couple and other available relatives. DNA was extracted and digested with appropriate restriction enzymes. A maximum of 13 restriction fragment length polymorphisms were used to determine the informativeness of the test. Where possible this was done before the pregnancy occurred..$^{5-712}$

\section{PRENATAL PROCEDURES}

When a prenatal test was requested, transcervical chorion villus biopsy was used to obtain fetal DNA samples at 9 to 11 weeks of gestation. If termination of the pregnancy was requested based on the results of the DNA

Table 2 Responses by age and sex of those at risk candidates who said they would use prenatal testing to the question: "If the results of the prenatal test showed that the fetus probably does have the gene for HD, would you . . .?" $(n=167$ responses, missing = 2).

\begin{tabular}{|c|c|c|c|c|}
\hline & \multicolumn{3}{|c|}{ Age categories } & \multirow[b]{2}{*}{ Total } \\
\hline & $\begin{array}{c}<30 \\
\text { No }(\%)\end{array}$ & $\begin{array}{c}30-40 \\
\text { No }(\%)\end{array}$ & $\begin{array}{c}>40 \\
\text { No }(\%)\end{array}$ & \\
\hline \multicolumn{5}{|l|}{ All candidates } \\
\hline Complete pregnancy & $11(29 \cdot 7)$ & $12(16 \cdot 6)$ & $18(31 \cdot 0)$ & $41(24 \cdot 6)$ \\
\hline Terminate pregnancy & $6(16 \cdot 2)$ & $39(54 \cdot 2)$ & $22(38.0)$ & $67(40 \cdot 1)$ \\
\hline Uncertain & $20(54 \cdot 1)$ & $21(29 \cdot 2)$ & $18(31.0)$ & $59(35 \cdot 3)$ \\
\hline Total & $37(100)$ & $72(100)$ & $58(100)$ & $167(100)$ \\
\hline \multirow{2}{*}{\multicolumn{5}{|c|}{ Female candidates }} \\
\hline & & & & \\
\hline Complete pregnancy & $6(25 \cdot 0)$ & $5(11.9)$ & $14(36 \cdot 8)$ & $25(24 \cdot 0)$ \\
\hline Terminate pregnancy & $4(16.7)$ & $24(57 \cdot 1)$ & $13(34 \cdot 2)$ & $41(39 \cdot 4)$ \\
\hline Uncertain & $14(58 \cdot 3)$ & $13(31 \cdot 0)$ & $11(28.9)$ & $38(36 \cdot 5)$ \\
\hline Total & $24(100)$ & $42(100)$ & $38(100)$ & $104(100)$ \\
\hline \multirow{2}{*}{\multicolumn{5}{|c|}{ Male candidates }} \\
\hline & & & & \\
\hline Complete pregnancy & $5(38.5)$ & $7(23 \cdot 3)$ & $4(20 \cdot 0)$ & $16(25 \cdot 4)$ \\
\hline Terminate pregnancy & $2(15.4)$ & $15(50 \cdot 0)$ & $9(45.0)$ & $26(41 \cdot 3)$ \\
\hline Uncertain & $6(46 \cdot 2)$ & $8(26 \cdot 7)$ & $7(35.0)$ & $21(33 \cdot 3)$ \\
\hline Total & $13(100)$ & $30(100)$ & $20(100)$ & $63(100)$ \\
\hline $\mathrm{p}$ value & & & & 0.293 \\
\hline
\end{tabular}

analysis, this was done by evacuation as soon after the results as possible.

\section{STATISTICAL ANALYSIS}

$\chi^{2}$ analyses (for categorical variables) and $t$ tests (for continuous variables) were used to determine whether there were any differences on baseline demographic variables between the groups requesting and not requesting prenatal testing. $\chi^{2}$ tests were also used to determine whether predictive testing participants responded differently based on their age and sex to questions regarding their attitudes to prenatal testing and termination of pregnancy. One way analysis of variance (ANOVA), or a non-parametric equivalent (Kruskall-Wallis), and $t$ tests were used to test for differences in psychological distress and depression at baseline and follow up points between subjects who received a modification of risk (increased or decreased) in adult predictive testing, and those who received prenatal testing results. Difference scores (that is, follow up score minus baseline score) were used in the analysis of follow up data. For all analyses, 0.05 was set as the criterion for statistical significance.

\section{Results}

GENERAL ATTITUDES TOWARDS PRENATAL TESTING

A total of 400 adult predictive testing candidates completed the prenatal knowledge questionnaire. Of these, $285(71 \%)$ understood how definitive prenatal testing was performed and $315(79 \%)$ were aware that exclusion testing was possible. However, only $149(37 \%)$ understood a major principle of exclusion testing, that it is not necessary to determine the risk of the parent in order to do exclusion testing for the fetus. Three hundred and thirty-nine $(85 \%)$ candidates knew that a fetus's risk cannot be higher than that of the at risk parent. The majority of candidates (374 or $94 \%$ ) understood that the decision to terminate the pregnancy was a personal one which had to be made by the couple themselves.

Of the $\mathbf{3 9 0}$ male and female adult predictive testing candidates who completed the attitude questionnaire, $169(43 \%)$ indicated they would use prenatal testing if they, or their spouse, became pregnant (table 1). For female participants, projected use of prenatal testing was related to the age of the respondent $(p=0.009)$. More women over the age of 40 years said they would use prenatal testing than did younger women. No such association was observed for male participants $(p=0 \cdot 218)$.

Of the 169 at risk subjects who said they would use prenatal testing, $67(40 \%)$ said they would want to terminate the pregnancy if the prenatal test showed an increased risk for the fetus, 41 of the candidates $(25 \%)$ said they would want to complete the pregnancy, 50 $(35 \%)$ were uncertain, and two did not respond (table 2). Male and female at risk candidates did not differ in their attitudes towards termination of an increased risk pregnancy. However, for female participants there was an 
association between age and attitude towards termination $(p=0.003)$. Only four $(17 \%)$ women below the age of 30 said they would want to terminate the pregnancy if the fetus was at increased risk for HD; a much larger proportion of women $(46 \%) 30$ years of age or more said they would want to terminate the pregnancy. On the other hand, the under 30 age group had a larger proportion $(58 \%)$ of women than those in the 30 years or more age group $(30 \%)$ who were uncertain about what they would want to do.

As would be expected, a strong association was found between the age of study participants and the number of children per family $(p=0.0001)$. The majority of persons over 40 years of age $(78 \%)$ already had two or more children when they entered the CCSPT (table 3 ) while most of the participants under 30 $(76 \%)$ had no children.

DEMAND FOR PRENATAL TESTING AND OUTCOME OF PREGNANCIES

Eighteen prenatal tests were requested by the 14 at risk subjects and their spouses in the prenatal testing programme. One couple requested three prenatal tests and two couples requested two prenatal tests each. However, of the 18 prenatal tests requested, seven were not performed. Reasons for cancellation of the test included miscarriage $(n=3)$, non-acceptance of termination as an option for the pregnancy $(n=4)$, and termination of pregnancy for personal reasons $(n=1)$, the most important of which was the participant's own increased risk predictive test result. Thus, in total, 11 prenatal tests (five definitive and six exclusion) were performed for the seven couples who remained in the study. The outcome of each test is stated in table 4.

Six out of the seven increased risk pregnancies were terminated. As noted above, three couples in our study had prenatal testing on more than one occasion. One couple, the female member of which was affected with $\mathrm{HD}$, requested three definitive tests. On the first test, the fetus was found to be at high risk for $\mathrm{HD}$ and the pregnancy was terminated. A

Table 3 Number of children per family by age of at risk candidate $(n=402)$.

\begin{tabular}{lccc}
\hline No of children & $<30$ years & $30-40$ years & $>40$ years \\
\cline { 2 - 4 } & No $(\%)$ & No $(\%)$ & No $(\%)$ \\
\hline 0 & $87(76 \cdot 3)$ & $62(36 \cdot 9)$ & $12(10 \cdot 0)$ \\
1 & $14(12 \cdot 3)$ & $35(20 \cdot 8)$ & $14(11 \cdot 7)$ \\
2 or more & $13(11 \cdot 4)$ & $71(42 \cdot 3)$ & $94(78 \cdot 3)$ \\
Total & $114(100)$ & $168(100)$ & $120(100)$ \\
p value & & & $0 \cdot 0001$ \\
\hline
\end{tabular}

Table 4 Results of 11 prenatal tests performed for seven couples.

\begin{tabular}{lccc}
\hline $\begin{array}{l}\text { Results of } \\
\text { prenatal test }\end{array}$ & $\begin{array}{c}\text { Definitive tests } \\
\text { (3 couples) }\end{array}$ & \multirow{2}{*}{$\begin{array}{c}\text { Exclusion tests } \\
(4 \text { couples })\end{array}$} \\
\cline { 2 - 2 } & Status of at risk subject & \\
\cline { 2 - 3 } & Affected & Increased risk & \\
\hline Increased risk & 1 & 1 & 5 \\
Decreased risk & 3 & 0 & 1 \\
Total & 4 & 1 & 6 \\
\hline
\end{tabular}

decreased risk result was given in the second pregnancy but the fetus was miscarried. In the third pregnancy, a decreased risk result was again given but, this time, the pregnancy was completed. Two other couples had two exclusion tests each. In each case, the fetus was found to be at increased risk and the pregnancy was terminated. Both couples went on to have a third pregnancy during which neither chose to use prenatal testing.

\section{DEMOGRAPHIC CHARACTERISTICS OF} PARTICIPANTS WHO CHOSE OR DECLINED PRENATAL TESTING

Twenty-four people who entered the adult predictive testing programme, and who knew about the availability of prenatal testing, chose not to use it when they or their partner became pregnant. These at risk subjects were compared, on a set of sociodemographic variables, with the 14 at risk subjects who did request prenatal testing (table 5). There were no significant differences between the two groups in terms of sex ratio, age, or education level. However, the mean number of children per family was significantly different $(p=0.02)$. More subjects in the group not choosing prenatal testing had already begun their families. The religious practices of the two groups also differed significantly $(p=0.05)$. More subjects in the group that did not choose prenatal testing indicated they were practising members of a religious organisation.

\section{REASONS GIVEN FOR DECLINING PRENATAL}

TESTING

The 24 subjects who chose not to participate in prenatal testing were asked to complete an additional questionnaire so that we could ascertain the reasons why they chose not to have the test. Spouses were sent a similar questionnaire. Seventeen $(71 \%)$ of the candidate questionnaires and $16(67 \%)$ of the spouses' questionnaires were returned. The 17 subjects who completed the candidate questionnaire were representative of the original group of 24 in terms of sex ratio and age.

In response to a question regarding attitude towards termination of pregnancy, only $3 / 17$ $(18 \%)$ respondents felt termination should not be available under any circumstances. Ten

Table 5 Sociodemographic comparison of groups choosing or declining prenatal testing.

\begin{tabular}{|c|c|c|c|}
\hline Variable & $\begin{array}{l}\text { Prenatal test } \\
(\mathrm{n}=14)\end{array}$ & $\begin{array}{c}\text { No prenatal } \\
\text { test } \\
(n=24)\end{array}$ & $\mathrm{p}$ \\
\hline $\begin{array}{l}\text { Mean age } \\
\quad(\min -\max )\end{array}$ & $\begin{array}{c}26 \cdot 8 \\
(17-36)\end{array}$ & $\begin{array}{c}30 \cdot 1 \\
(21-41)\end{array}$ & NS \\
\hline $\begin{array}{l}\text { Sex } \\
\text { Males } \\
\text { Females }\end{array}$ & $\begin{array}{l}5(36 \%) \\
9(64 \%)\end{array}$ & $\begin{array}{r}8(33 \%) \\
16(67 \%)\end{array}$ & NS \\
\hline $\begin{array}{l}\text { Mean number of } \\
\text { children } \\
\text { (min-max) }\end{array}$ & $\begin{array}{c}0 \cdot 21 \\
(0 \cdot 0-2 \cdot 0)\end{array}$ & $\begin{array}{c}0.96 \\
(0.0-4.0)\end{array}$ & $p=0.02$ \\
\hline $\begin{array}{l}\text { Education } \\
<\text { High school } \\
>\text { /High school }\end{array}$ & $\begin{array}{r}2 \\
11\end{array}$ & $\begin{array}{r}4 \\
19\end{array}$ & NS \\
\hline $\begin{array}{l}\text { Religious practices } \\
\text { Religious group } \\
\text { member } \\
\text { Non-religious/ } \\
\text { non-practising }\end{array}$ & $\begin{array}{r}3 \\
10\end{array}$ & $\begin{array}{r}12 \\
9\end{array}$ & $\mathrm{p}=0.05$ \\
\hline
\end{tabular}


$(59 \%)$ subjects felt that termination should only be available under certain circumstances, three $(18 \%)$ felt that it should be available on demand, and one $(5 \%)$ person did not respond to the question.

In indicating their most important reasons for not having prenatal testing, $14 / 17(82 \%)$ subjects stated they did not have prenatal testing because of their belief that a cure will be found before their children develop HD (table 6$)$. Many of the respondents (12/17 or $71 \%$ ) further indicated that their desire to have a child outweighed the distant threat that the child might some day develop HD. Approximately half the respondents $(7 / 17)$ had serious concerns about the safety of the prenatal procedure and seven indicated that they want to determine their own status before making any decisions about prenatal testing.

Spouses' reasons for not wanting prenatal testing were similar to those of the at risk respondents (table 6). However, the spouse's opposition to prenatal testing was cited as one reason why five at risk subjects chose not to have the prenatal test.

\section{ATTITUDES OF PERSONS RECEIVING A LOW RISK} ADULT PREDICTIVE TEST RESULT

Nine of the 47 women who became pregnant during the study period did not require the prenatal test because they or their partner had received a decreased risk result from adult predictive testing. In a questionnaire completed before receiving their adult risk result the nine at risk members of each couple were asked about their reproductive plans. Five $(56 \%)$ of the nine indicated they would not have (more) children if their risk was increased or if the testing was uninformative, three $(33 \%)$ indicated they wanted (more) children regardless of the predictive test result, and one person did not respond to the question.

\section{PSYCHOLOGICAL ASSESSMENT}

Psychological assessment was available for only six of the seven at risk candidates who

Table 6 Reasons given by questionnaire respondents for declining prenatal testing. Subjects were allowed to choose up to five reasons from this list.

\begin{tabular}{lcc}
\hline \multicolumn{1}{c}{ Reasons } & $\begin{array}{c}\text { No of times given as a } \\
\text { reason }\end{array}$ \\
\cline { 2 - 3 } & $\begin{array}{c}\text { AR } \\
\text { persons } \\
\text { (n=17) }\end{array}$ & $\begin{array}{c}\text { Spouses } \\
\text { (n=16) }\end{array}$ \\
\hline $\begin{array}{l}\text { Candidate believed that a cure would be found in time for his/her } \\
\text { children }\end{array}$ & 14 & 11 \\
$\begin{array}{l}\text { Candidate's desire for a child outweighed the possibility that the child } \\
\text { may someday develop HD }\end{array}$ & 12 & 10 \\
$\begin{array}{l}\text { Candidate could not handle the emotional and psychological } \\
\text { consequences of an elective termination of a pregnancy }\end{array}$ & 7 & 8 \\
$\begin{array}{l}\text { Candidate had serious concerns regarding the safety of the prenatal test } \\
\text { Candidate wanted to determine his/her status before making a decision }\end{array}$ & 7 & 7 \\
$\begin{array}{l}\text { Candidate did not beling } \\
\text { morally, or religiously justifiable }\end{array}$ & 7 & 5 \\
$\begin{array}{l}\text { Candidate's partner was opposed to prenatal testing } \\
\text { Candidate felt that the prenatal test was too inaccurate to risk the } \\
\text { termination of a potentially healthy child }\end{array}$ & 5 & 7 \\
$\begin{array}{l}\text { Candidate felt the child should make his/her own decision about } \\
\text { predictive testing }\end{array}$ & 5 & 6 \\
$\begin{array}{l}\text { Candidate felt that to test the current pregnancy would be unfair to } \\
\text { previous children who were not tested }\end{array}$ & 2 & 0 \\
$\begin{array}{l}\text { Prenatal testing was not possible in candidate's family } \\
\text { Candidate was unaware that prenatal testing was possible/available }\end{array}$ & 2 & 1 \\
\hline
\end{tabular}

participated in prenatal testing, as one subject refused to comply with the follow up protocol and very few of the partners completed the psychosocial questionnaires. The mean scores on the General Severity Index and the Beck Depression Inventory for the first prenatal test are shown in table 7 . The means are all within the normal range for both these standardised measures of psychological distress and depression. A reduction in distress was observed at the two month follow up but this decline failed to reach statistical significance $(p=0 \cdot 11)$. The six month follow up showed a change back towards the baseline level of distress.

\section{Discussion}

Prenatal testing for HD has been offered in Canada for approximately five years. This continuing national programme has provided a unique opportunity to study the knowledge and attitudes of people at risk for HD who choose or decline prenatal testing. During this period, 411 at risk subjects have participated in adult predictive testing, while only 14 at risk subjects have entered the prenatal testing programme. Of these 14 couples, only seven went on to have the prenatal test. The other seven withdrew, primarily because of miscarriages or because they did not consider termination of pregnancy to be an option. Thus, among those in the CCSPT who were eligible for the prenatal test, demand has been low $(7 / 38$ or $18 \%)$, certainly below the expected demand based on the four American studies conducted before the development of these programmes. ${ }^{8-11}$

Acknowledging the small sample size, two factors were found in our study to be associated with the decision to participate in prenatal testing. The first was the number of existing children in the family. More of the persons who requested prenatal testing were just starting their families compared with those who decided against prenatal testing. It may be that subjects who already have children are less willing to participate in prenatal testing because they do not wish to have knowledge about the risk status of some of their children but not others. The second factor associated with the decision was religious conviction. Persons in our study who chose prenatal testing were less likely to be practising members of a religious organisation than those who chose not to participate in prenatal testing. Religious conviction and a willingness to consider termination as an option for a fetus at increased risk are likely to have an associated influence on the decision to use or not use prenatal testing. In fact, it may be the issue of termination that is

Table 7 Comparison of mean scores of the prenatal group on General Severity Index (GSI) of the SCL $90(R)$ and Beck Depression Inventory $(B D I)$ at baseline and two and six month follow ups $(n=6)$.

\begin{tabular}{lccc}
\hline & \multicolumn{3}{c}{$\begin{array}{c}\text { Mean (SD) } \\
{[\text { min-max] }}\end{array}$} \\
\cline { 2 - 4 } Tests & Baseline & 2 months & 6 months \\
\hline GSI & $49 \cdot 3(11 \cdot 5)$ & $41 \cdot 3(6 \cdot 9)$ & $45 \cdot 7(11 \cdot 3)$ \\
BDI & {$[30-63]$} & {$[34-51]$} & {$[30-57]$} \\
& $5 \cdot 5(4 \cdot 1)$ & $2 \cdot 5(1 \cdot 8)$ & $3 \cdot 2(3 \cdot 0)$ \\
& {$[0-12]$} & {$[0-4]$} & {$[0-8]$} \\
\hline
\end{tabular}


the more important factor in the decision process than religious conviction in itself. As noted above, rejection of termination as an option was a major reason for the withdrawal of four of the $14(28.5 \%)$ subjects who initially requested prenatal testing, and was the main reason seven subjects, out of $17(41 \%)$ who became pregnant while in the adult predictive testing programme, chose not to have the prenatal test.

Although the prospect of terminating a fetus at increased risk prevented several persons in our study from having the prenatal test, the most frequently cited reason for refusing the prenatal test was the belief that a cure would be found in time for the children. Recent publicity concerning genetic discoveries may have raised the expectations of persons at risk for HD. While the eventual cloning of the HD gene could result in effective therapy this is by no means a certainty.

Nine of the 47 prospective parents in our study chose to use adult predictive testing as a means of ensuring that they were at low risk of transmitting the gene for HD to their child. A low risk result provided at least five of these couples with the opportunity to have children that they might not have had otherwise.

Age was found to differentiate between persons in the adult predictive testing programme who said they would, or would not, use prenatal testing if they became pregnant. More women over the age of 40 said they would use prenatal testing than women in the younger age categories. Since many of the women in this age group would already have completed their families, questions concerning the use of prenatal testing would require that they predict their response to a hypothetical and, in many cases, unlikely event. A younger age group of women, for whom family planning may be a more immediate concern, could be expected to be somewhat more cautious; their responses might be tempered by the knowledge that a real decision about prenatal testing could be faced in the near future. None of our study participants over the age of 40 became pregnant, so it was not possible to ascertain actual use for this age group.

Of all those who said they would use prenatal testing if they became pregnant, the under 30 age group were the most uncertain about what action they would take in the event the fetus was found to be at increased risk; they were the least likely to say they would terminate the pregnancy. Thus, for this younger group, termination of a high risk fetus appears to be a largely unresolved issue.

Six out of the seven subjects in our cohort who participated in prenatal testing, and received an increased risk result, chose to terminate the pregnancy. The terminations were done within a very short time after the results were received and the counsellors played an important role in making the arrangements with as little stress and delay as possible. It is likely, based on this experience and the experience in Wales, ${ }^{17}$ that most high risk pregnancies will be terminated.

The couple who received the increased pre- natal risk and did not terminate the pregnancy found that termination was too difficult an option when they were actually faced with the choice. They began to doubt the at risk parent's increased risk result and felt that the prenatal test was too inaccurate to risk the termination of a potentially healthy child. Interestingly, this couple went on to have a second pregnancy in which they chose not to have any testing.

Parents who do not accept termination of pregnancy as an option but who wish to have the prenatal test have to balance the complexities and difficulties associated with the birth of a child at a known high risk for HD against the possibility of obtaining information that their continuing pregnancy might be at low risk. With counselling, patients have understood that the birth of a child at high risk would be equivalent to performing predictive testing in childhood. The only justification for doing predictive testing in childhood is if the advantage can clearly be shown for the child. ${ }^{21}$ There is currently no known treatment which might prevent or delay the onset of HD and predictive testing in childhood could be disadvantageous to the child because of distortions in parent-child or sib-sib relationships. Such distortions could result in a significant diminishing of self esteem and sense of worth for the developing child. The situation becomes even more complicated for exclusion testing where the child's risk is close to $50 \%$ and, therefore, similar to that of the at risk parent. The onset of symptoms in the parent would be equivalent to a definitive predictive test in the child as each of them would in all likelihood have inherited the same chromosome 4 . When the implications of prenatal testing for HD are explained to the parents who do not consider termination of pregnancy an option, they usually decide not to pursue prenatal testing. This finding, coupled with the uncertainty about termination which was observed among non-pregnant at risk subjects, highlights the importance of providing continuing education and in depth counselling in order to explain the intricacies and complexities of prenatal testing to every prospective couple.

Only one at risk subject in our study said he did not know that prenatal testing was an available option. Thus, lack of awareness does not appear to have been a factor influencing the decision to use prenatal testing. In addition, lack of knowledge about the details of prenatal testing was not a factor as most of the at risk subjects entered the predictive testing programme with a good understanding of the prenatal test.

However, in contrast, the implications of exclusion testing were not appreciated by $63 \%$ of at risk persons. Many subjects did not realise that the risk status of the fetus could be determined without first establishing the status of the at risk parent. This finding is similar to that previously described by Tyler et $a l^{17}$ who found that nearly $90 \%$ of their cohort were also confused by certain aspects of exclusion testing. Clearly additional time and care 
needs to be spent when counselling persons who are considering prenatal exclusion testing.

A major concern about both prenatal and adult predictive testing relates to the impact these new technologies have on the quality of life of the participants. We have previously shown that predictive testing for HD has led to an improvement in the quality of life for some at risk subjects, whether they received a decreased or an increased risk result. ${ }^{22-24}$ To date, there have been no catastrophic psychological responses (such as emotional breakdown or suicide) to prenatal testing for HD. The average scores of the prenatal testing group on the General Severity Index of the SCL $90(R)$ and the Beck Depression Inventory have also been well within the normal ranges both at baseline and at the two follow up assessments. Moreover, with the exception of one person who was mildly depressed at baseline, none of the individual scores was high enough to reach clinical criteria for distress or depression. Although the participants in our study have coped reasonably well with prenatal testing, definitive conclusions about the psychological effects of prenatal testing would be premature given the small number of persons in our prenatal group and the limited amount of follow up data available for analysis.

A different kind of difficulty has been expressed by some couples during the counselling process. Some couples who participated in prenatal testing felt there was a technological imperative to use the test in every subsequent pregnancy. These couples felt that the availability of the test impelled them to use it in the first pregnancy. Then, they could only justify the initial use of prenatal testing if they continued to use the same technology in future pregnancies. As such, several couples have had repeated prenatal tests including one subject who had three prenatal tests and two who each requested two tests. Careful in depth counselling is needed to free couples from the imperative of having to make the same choice they made in previous pregnancies. We have explained to couples in this situation that their circumstances may be different now from what they were when they had the previous test, and that careful consideration has to be made before deciding that the current prenatal test is warranted. The psychological suffering which might result from the successive loss of repeated pregnancies has to be balanced against the possible relief of hearing that their current pregnancy is at low risk for having inherited the gene for HD. Freeing patients from the technological imperative and allowing them to make an independent choice during every pregnancy is an important part of the pre-test counselling process.

In view of the complexity of counselling for both prenatal definitive and prenatal exclusion testing, the informativeness of DNA testing should, where possible, be established before pregnancy so there is sufficient time for the patients to assimilate all the information about prenatal testing. In our cohort, only three of the seven couples who had prenatal testing requested information about the test, and entered the programme, before becoming pregnant. Based on our experience, therefore, it could be expected that many subjects who enter prenatal testing will already be pregnant. This places the couple as well as the counsellors under pressure to process this complex information within a limited time frame. It is important to educate the at risk population about the need for requesting prenatal testing before becoming pregnant.

The cloning of the gene for $\mathrm{HD}$ will have an impact on the demand for and attitudes of at risk subjects towards prenatal testing. If $\mathrm{HD}$ results from a single or a few mutations there will be an opportunity for definitive testing for patients who were previously unable to choose this option. Three out of the four persons in our study who chose exclusion testing did not have enough family members to permit definitive testing. If the chances for definitive testing improve, requests for exclusion testing might be reduced. On the other hand, if the accuracy of the prenatal test improves, which it would if one of only a few specific mutations causing HD was identified, some subjects who would not have had prenatal testing because of the inaccuracy of the test might decide to proceed. Five of 17 members of our cohort who chose not to use prenatal testing felt that the prenatal test was too inaccurate to risk termination of a potentially healthy child. All or any of these persons might have chosen prenatal testing if the mutation causing HD were known in their family.

The possible increase in requests for prenatal testing owing to improvements in the test's accuracy are likely to be offset by other factors. Optimism about a cure was the predominant reason for not considering prenatal testing. The possibility of effective therapy which may arise as a result of the cloning of the gene for Huntington's disease is likely to reduce still further the demand for prenatal testing, since termination of a pregnancy for a curable adult onset illness is likely to be even less acceptable. This has been shown for other late onset autosomal dominant disorders, such as polycystic kidney disease, for which there are some effective therapies which might retard progression of this illness. As such, prenatal testing for this condition is viewed as a very unpopular option for which demand is exceedingly low. ${ }^{25}$ Therefore as further treatments are developed or where there is a strong belief in the patient population that effective therapy is imminent, prenatal testing for late onset genetic disorders is not likely to be readily accepted.

Despite the extremely complex nature of prenatal testing for HD and the need for in depth counselling and support, prenatal testing should still be offered as an option for the small number of subjects who would make this choice. Continued long term assessment of those who choose to participate in prenatal testing is needed before reaching final conclusions about its impact on the psychological well being of persons at risk for Huntington's disease. The long term effects of participating 
in multiple prenatal tests needs to be documented as well.

We thank our colleagues in the Canadian Collaborative Study of Predictive Testing for Huntington's Disease. This work is supported by the MRC of Canada, the National Health Research Development Program (NHRDP), a Western Canadian Private Foundation, the MSI Foundation of Alberta, and the Huntington Society of Canada. Michael Hayden is a career investigator of the British Columbia Children's Hospital.

1 Reeders ST, Breuning MH, Davies KE, et al. A highly polymorphic DNA marker linked to adult polycystic disease on chromosome 16. Nature 1985;317:542-4.

2 Goate A, Chartier-Harlin MC, Mullan M, et al. Segregation of a missense mutation in the amyloid precursor protein gene with familial Alzheimer's disease. Nature 1991;349:704-6.

3 Collinge J, Poulter M, Davis MB, et al. Presymptomatic detection or exclusion of Prion protein gene defects in families with inherited Prion diseases. Am 7 Hum Genet 1991;49:1351-4.

4 Gusella JF, Wexler NS, Conneally PM, et al. A polymorphic DNA marker genetically linked to Huntington's phic DNA marker genetically
disease. Nature 1983;306:234-8.

5 Wasmuth JJ, Hewitt J, Smith B, et al. A highly polymorphic locus tightly linked to the Huntington's disease gene. phic locus tightly linked

6 Hayden MR, Robbins C, Allard D, et al. Improved predictive testing for Huntington's disease by using three linked DNA markers. Am f Hum Genet 1988;43:689-94.

7 Fahy M, Robbins C, Bloch M, Turnell RW, Hayden MR. Different options for prenatal testing for Huntington's disease using DNA probes. $\mathcal{F}$ Med Genet 1989;26:353-7.

8 Markel DS, Young AB, Penney JB. At-risk person's attitudes toward presymptomatic and prenatal testing of Huntington's disease in Michigan. Am $7 \mathrm{Med}$ Genet 1987;26:295-305.

9 Meissen GJ, Berchek RL. Intended use of predictive testing by those at risk for Huntington's disease. Am f Med Genet 1987;26:283-93.
10 Kessler S, Field T, Worth L, Mosbarger H. Attitudes of persons at risk for Huntington's disease toward predictive testing. Am f Med Genet 1987;26:259-70.

11 Mastromauro C, Myers RH, Berkman B. Attitudes toward presymptomatic testing in Huntington's disease. $\mathrm{Am} \mathrm{J}$ Med Genet 1987;26:271-82.

12 Hayden MR, Hewitt J, Kastelein JJP, et al. First-trimester prenatal diagnosis for Huntington's disease with DNA probes. Lancet $1987 ; \mathbf{i}: 1284-5$.

13 Quarrell OWJ, Meredith AL, Tyler A, Youngman S, Upadhyaya M, Harper PS. Exclusion testing for Huntington's disease in pregnancy with a closely linked DNA marker. Lancet 1987;i:1281-3.

14 Millan FA, Curtis A, Mennie M, et al. Prenatal exclusion testing for Huntington's disease: a problem of too much information. $\mathcal{f}$ Med Genet 1989;26:83-5.

15 Spurdle A, Kromberg J, Rosendorff J, Jenkins T. Prenatal diagnosis for Huntington's disease: a molecular and psydiagnosis for Huntington's disease: a molecula

16 Craufurd D, Kerzin-Storrar L, Dodge A, Harris R. Uptake of presymptomatic predictive testing for Huntington's of presymptomatic predictive
disease. Lancet 1989;ii:603-5.

17 Tyler A, Quarrell OWJ, Lazarou LP, Meredith AL, Harper PS. Exclusion testing in pregnancy for Huntington's disease. F Med Genet 1990;27:488-95.

18 Fox S, Bloch M, Fahy M, Hayden MR. Predictive testing for Huntington disease. I. Description of a pilot project in British Columbia. Am $\mathcal{F}$ Med Genet 1989;32:21 1-16.

19 Derogatis LR. SCL 90 administration, scoring and procedures: manual II for the $R$ (revised) version. Baltimore: Johns Hopkins University Press, 1977.

20 Beck A, Ward C, Mendelson M, Mock J, Erbaugh J. An inventory for measuring depression. Arch Gen Psychiatry 1961;4:53-63.

21 Bloch M, Hayden MR. Opinion: predictive testing for Huntington disease in childhood: challenges and implications. Am f Hum Genet 1990;46:1-4.

22 Wiggins $\mathrm{S}$, Whyte $\mathrm{P}$, Huggins $\mathrm{M}$, et al. The psychological consequences of predictive testing for Huntington's disconsequences of predictive testing for
ease. $N$ Engl f Med 1992;327:401-5.

23 Huggins $M$, Bloch $M$, Wiggins S, et al. Predictive testing for Huntington disease in Canada: adverse effects and unexpected results in those receiving a decreased risk. $A m$ $\mathcal{f}$ Med Genet 1992;42:508-15.

24 Bloch M, Adam S, Wiggins S, Huggins M, Hayden MR. Predictive testing for Huntington disease in Canada: the experience of those receiving an increased risk. $A m \mathcal{F} \mathrm{Med}$ Genet 1992;42:499-507.

25 Kerzin-Storrar L, Khan AA, Walters EA, et al. A regional genetic family register: opportunity for active - rather than reactive - genetic counselling. Am $\mathcal{f}$ Hum Genet $1991 ; 49$ (suppl):42. 